DOI: $10.29413 /$ ABS.2018-3.4.18

удК 616.381-007.274-092.9

Шурыгина И.А. ', Аюшинова Н.Н. ', Родионова П.В. ', Чепурных Е.Е. ', Шурыгин М.Г. ${ }^{1}{ }^{2}$ ВОВЛЕЧЕНИЕ ЈNК МАРК КАСКАДОВ В ФОРМИРОВАНИЕ СПАЕЧНОГО ПРОЦЕССА В БРЮШНОЙ ПОЛОСТИ

\author{
1 ФГБНУ «Иркутский научный центр хирургии и травматологии» \\ (664003, г. Иркутск, ул. Борцов Революции, 1, Россия) \\ ${ }^{2}$ АО «Фармасинтез»
}

(664007, г. Иркутск, ул. Красногвардейская, 23, Россия)

Формирование спаечного процесса в брюшной полости - одно из наиболее частых осложнений интраабдоминальной хирургии

Цель исследования: оценить активацию ЈNК МАРК каскада при экспериментальном спаечном процессе. Материалы и методы. Экспериментальные исследования проведены на 40 самиах крыс линии Wistar (9 мес.). Моделировали спаечный процесс в брюшной полости. В сроки от 2 часов (2, 6, 12 часов) до 30 суток (1, 3, 7, 14, 30 суток) проведена оценка JNK МАРК каскада в зоне повреждения серозной оболочки с использованием иммуногистохимических методов (окраска на JNK1 Phospho (pT183) / JNK2 Phospho (pT183) / JNK3 Phospho (pT221)) u real-time ПЦР (набор MAP Kinase Signaling Pathway RT ${ }^{2}$ - Profiler ${ }^{\text {TM }}$ PCR Array (Qiagen)).

Результаты. Установлено, что экспрессия фосфорилированной части ЈNКМАРКкаскадов имеет волнообразную динамику с двумя пиками - на 3-и и 14-е сутки. Определено, что в процесс вовлекаются все три ЈNК каскада, причём на 3-и сутки синхронно активируются все каскады группы JNK (JNK1 повышается 12-кратно по сравнению с группой интактных животных, JNK2 - 8-кратно, JNK3 - 10-кратно). На 14-е сутки наиболее интенсивно повышается активность ЈNK3 каскада - в 30 раз (для JNK1 - примерно в 6 раз, JNК2 - в 12 раз). Заключение. Установлена значительная активация исследуемых МАРК каскадов на 14-е сутки после травматического повреждения, что свидетельствует о необходимости длительной профилактики посттравматических изменений, в частности формирования спаечного процесса.

Ключевые слова: спаечный процесс, MAPK, JNK, моделирование

Для цитирования: Шурыгина И.А., Аюшинова Н.И., Родионова Л.В., Чепурных Е.Е., Шурыгин М.Г. Вовлечение JNK МАРК каскадов в формирование спаечного процесса в брюшной полости. Acta biomedica scientifica, 3 (4), 125-128, DOI 10.29413/ABS.2018-3.4.18.

\title{
INVOLVEMENT OF JNK MAPK CASCADES IN THE FORMATION OF ADHESIONS IN THE ABDOMINAL CAVITY
}

\author{
Shurygina I.A. ', Ayushinova N.I. ', Rodionova L.V. ' , Chepurnykh E.E. ', Shurygin M.G. 1, 2 \\ 1 Irkutsk Scientific Centre of Surgery and Traumatology \\ (ul. Bortsov Revolyutsii 1, Irkutsk 664003, Russian Federation) \\ 2 JSC Farmasintez \\ (ul. Krasnogvardeyskaya 23, Irkutsk 664007, Russian Federation)
}

Adhesive process in the abdominal cavity is one of the most frequent complications of intra-abdominal surgery. The aim of the study was to evaluate the activation of the JNK MAPK cascade during the experimental adhesion process. Materials and methods. Experimental studies were performed on 40 male Wistar rats ( 9 months old). We modeled the adhesive process in the abdominal cavity. At the time from 2 hours (2, 6, 12 hours) to 30 days (1, 3, 7, 14, 30 days), a JNK MAPK cascade was evaluated in the zone of damage to the serosa using immunohistochemical methods (painting on JNK1 Phospho (pT183) / JNK2 Phospho (pT183) / JNK3 Phospho (pT221)) and real-time PCR (the MAP Kinase Signaling Pathway RT2 - Profiler ${ }^{\mathrm{TM}}$ PCR Array (Qiagen) kit).

Results. We have found that the expression of the phosphorylated part of the JNK MAPK cascades has an undulating dynamics with two peaks on the 3rd and 14th day. It has been determined that all three JNK cascades are involved in the process, and all JNK cascades are synchronously activated on the 3rd day (JNK1 increases 12-fold in comparison with the group of intact animals, JNK2 is 8-fold, JNK3 is 10-fold). On the 14th day, the activity of the JNK3 cascade is the most intensively increased - 30 times (for JNK1 - about 6 times, JNK2 - 12 times).

Conclusion. Significant activation of MARK cascades has been established on the 14th day after traumatic injury, which indicates the need for long-term prevention of posttraumatic changes, in particular, the formation of adhesions.

Key words: adhesive process, MAPK, JNK, modeling

For citation: Shurygina I.A., Ayushinova N.I., Rodionova L.V., Chepurnykh E.E., Shurygin M.G. Involvement of JNK MAPK cascades in the formation of adhesions in the abdominal cavity. Acta biomedica scientifica, 3 (4), 125-128, DOI 10.29413/ABS.2018-3.4.18.

Формирование спаечного процесса в брюшной полости - одно из наиболее частых осложнений интраабдоминальной хирургии [1].

Проблемы патогенеза спаечного процесса обсуждаются уже более 100 лет. Однако до настоящего времени остаются нерешённые проблемы, не позволяющие подойти к разработке противоспаечных средств с высокой активностью [3].
По нашему мнению, одним из перспективных направлений в разработке таких подходов является управление спаечным процессом при помощи воздействия на внутриклеточные сигнальные каскадные механизмы.

Киназы N-концевой части фактора транскрипции Jun (c-Jun N-terminal kinases) (JNK) (по унифицированной классификации ЈNК1 - это МАРК8, JNК2 - МАРК9, JNK3 - MAPK10) - это стресс-активируемые про- 
теинкиназы. Они активируются под воздействием различных цитокинов, осмотического шока $[5,12]$. Эти киназы изменяют активность различных белков за счёт фосфорилирования. Известно, что МАРК8 и МАРК9 обнаружены во всех клетках и тканях [6, 8]. Высокая активность МАРК10 характерна для головного мозга, менее выраженная - для сердца и яичек $[6,7,9]$.

МАРК 8, 9 и 10 участвуют в дифференцировке клеток и их пролиферации. МАРК 8 и 9 вовлечены в апоптоз, индуцированный ультрафиолетовым излучением. МАРК 8 участвует также в апоптозе, индуцированном фактором некроза опухолей TNF- $\alpha$, в процессах нейродегенерации, воспалении, продукции цитокинов [10].

Поиск «ABDOMINAL ADHESION AND JNK» от 20.03.18 г., проведённый в Pubmed, выявил всего 7 работ, в которых рассматривается возможная вовлечённость JNK каскада в процесс спайкообразования.

L. Tian et al. (2018) связывают противовоспалительный и потенциальный противоспаечный эффект комбинации хитозана, целлюлозы и полисахарида морских водорослей со снижением активности основных классов МАРК, в частности, JNK, p38 и ERK. [11]. Такой же механизм действия предполагают у берберина гидрохлорида [13].

Однако до настоящего времени не опубликовано работ, раскрывающих вовлечение JNK каскада в спаечный процесс, сроки активации каскадных механизмов.

\section{ЦЕЛЬ ИССЛЕДОВАНИЯ}

Оценить активацию JNК МАРК каскада при экспериментальном спаечном процессе.

\section{МАТЕРИАЛЫ И МЕТОДЫ}

Моделировали асептический воспалительный процесс в брюшной полости разработанным нами методом $[2,4]$. Экспериментальные исследования проведены на 40 самцах крыс линии Wistar (9 мес.), по 5 животных на временную точку. Эксперименты выполнялись в соответствии с нормами гуманного обращения с животными, которые регламентированы «Guidelines of the Association for Assessment and Accreditation of Laboratory Animal Care, international» согласно протоколу, одобренному этическим Комитетом ИНЦХТ.

Выведение из эксперимента осуществлялось в сроки от 2 часов до 30 суток.

Фиксацию зон травмы брюшины, формирования спаечного процесса осуществляли в FineFix (Milestone, Италия), заливали материала в парафиновые блоки, изготавливали серийные срезы толщиной 5 мкм. Во все сроки наблюдения проводили иммуногистохимическое окрашивание образцов. В качестве первичных антител применяли JNK1 Phospho (рT183) / JNK2 Phospho (pT183) / JNK3 Phospho (pT221) (MAPK10) Rabbit Monoclonal Antibody (Epitomics, Clone ID: EPR5693, Cat. N 3893-1, Lot YH122306C), рабочее разведение 1:200. Использовали вторичные антитела Novolink Polymer (Novocastra, $\mathrm{REF}=7112$, Lot 6006512), меченные пероксидазой. Срезы докрашивали 0,02\% раствором гематоксилина Эрлиха.

Для оценки экспрессии генов, кодирующих JNK МАРК, забирался материал из зоны повреждения в области слепой кишки, помещался в раствор RNAlater (Ambion, Canada, Cat \#7020). Выделялась матричная
РНК, и с использованием наборов для ПЦР MAP Kinase Signaling Pathway RT ${ }^{2}$ - Profiler ${ }^{\mathrm{TM}}$ PCR Array (Qiagen $\mathrm{GmbH}$, Германия, кат. № PARN-061Z) исследовалась динамика изменения активности генов, кодирующих участвующие в данных каскадах белки.

Исследования проведены в сроки от 12 часов до 14 суток. Контролем служили исследования серозно-мышечного слоя слепой кишки у интактных животных $(n=5)$.

ПЦР проведён с использованием BioRAD CFX 96.

Статистическая обработка полученных результатов проведена с использованием оригинальной on-line программы анализа массивов данных, полученных на наборах RT2_Profiler PCR ARRAY фирмы SA Bioscience - http://www.qiagen.com/Products/Genes and Pathways/Data Analysis Center Overview Page/RT2 Profiler PCR Arrays Data Analysis Center/.

\section{РЕЗУЛЬТАТЫ ИССЛЕДОВАНИЯ}

Проведено изучение экспрессии маркеров JNK МАРК-каскадов в тканях зоны повреждения, причём именно их активной фосфорилированной формы (JNK1 Phospho (pT183) / JNK2 Phospho (pT183) / JNK3 Phospho (pT221)).

Установлено, что через 2 часа после операции наблюдалась минимальная активация JNK-каскадов. По интенсивности специфической окраски через 6 часов интенсивность экспрессии JNK нарастала, достигая умеренной выраженности, а через 12 часов - выраженной активности. К 3-м суткам активность JNKкаскадов резко возрастала, наблюдалась интенсивная окраска области травмы брюшины и субсерозного слоя (рис. 1).

На 7-е сутки интенсивность окраски в зоне повреждения снижалась до умеренной (рис. 2).

На 14-е сутки отмечен второй пик активности JNK МАРК-каскадов, при этом специфическая окраска была наиболее интенсивной за весь период наблюдения (рис. 3).

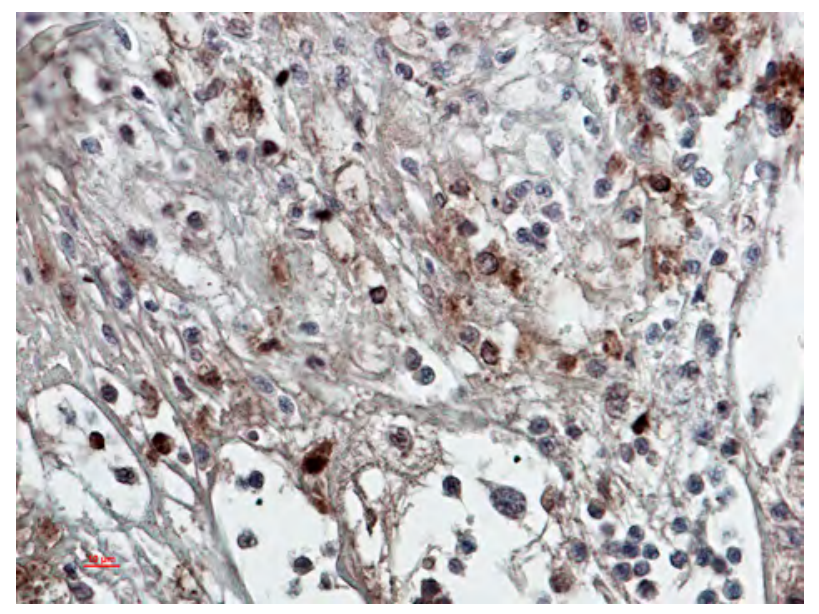

Рис. 1. 3-и сутки эксперимента. Ярко выраженная экспрессия JNK в субсерозном слое. Иммуногистохимия, первичные антитела - JNK1/ JNK2/ JNK3 Phospho (Epitomics), 1:200, докрашивание гематоксилином.

Fig. 1. The third day of the experiment. The pronounced expression of JNK in the subserose layer. Immunohistochemistry, primary antibodies - JNK1/JNK2/JNK3 Phospho (Epitomics), 1:200, staining with hematoxylin. 


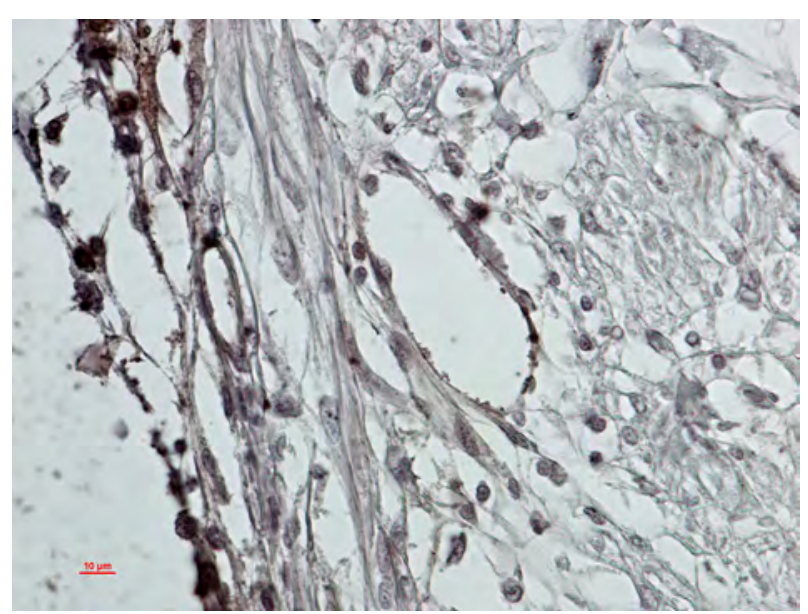

Рис. 2. 7-е сутки эксперимента, умеренно выраженная экспрессия JNK в области формирования спайки Иммуногистохимия, первичные антитела - JNK1/ JNK2/ JNK3 Phospho (Epitomics), 1:200, докрашивание гематоксилином.

Fig. 2. The 7 th day of the experiment, moderate expression of JNK in the area of adhesion formation. Immunohistochemistry, primary antibodies - JNK1/JNK2/JNK3 Phospho (Epitomics), 1:200, staining with hematoxylin.

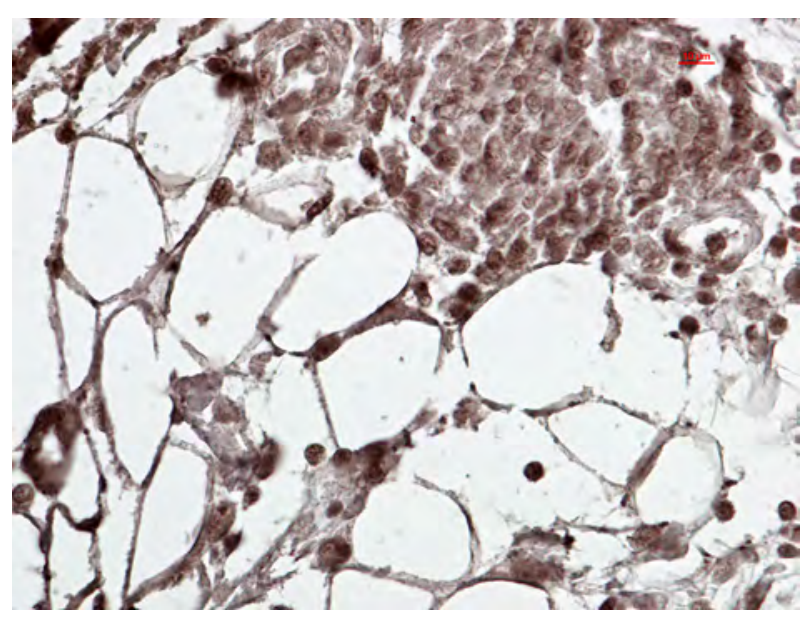

Рис. 3. 14-е сутки эксперимента. Выраженная экспрессия JNK в области формирования спайки «кишка сальник». Иммуногистохимия, первичные антитела - JNK1/ JNK2/ JNK3 Phospho (Epitomics), 1:200, докрашивание гематоксилином

Fig. 3. The 14th day of the experiment. Expressed expression of JNK in the area of formation of the adhesion "gut - omentum". Immunohistochemistry, primary antibodies - JNK1/JNK2/ JNK3 Phospho (Epitomics), 1:200, staining with hematoxylin.

К 30-м суткам активность каскадов снижалась.

Полученные результаты свидетельствуют о том, что экспрессия фосфорилированной части JNK MAPKкаскадов имеет волнообразную динамику с двумя пиками - на 3-и и 14-е сутки. Проведена оценка экспрессии генов JNK регуляторного каскадов в зоне повреждения слепой кишки. Результаты представлены по отношению количества копий мРНК последовательностей, кодирующих белки JNK-каскада, к регистрируемому уровню их экспрессии в области серозно-мышечного слоя слепой кишки у интактных животных.

При оценке экспрессия генов Mapk8 (JNK1), Mapk9 (JNK2), Mapk10 (JNK3) установлено, что пики активности наблюдались на 3-и и 14-е сутки (рис. 4).

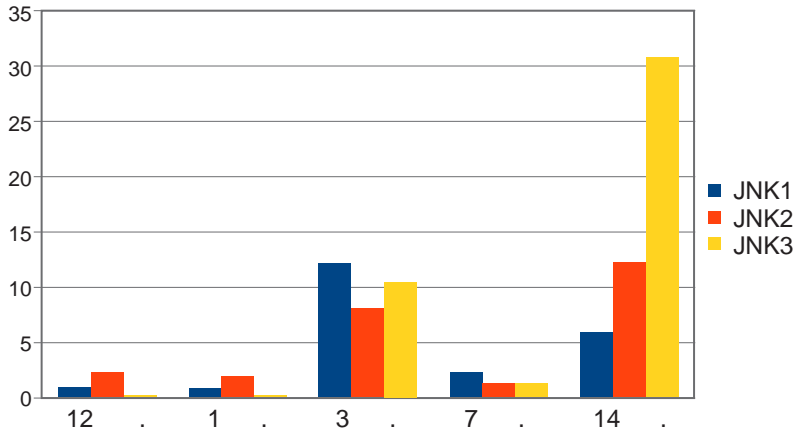

Рис. 4. Экспрессия JNK MAPK, кратность повышения по сравнению с интактными животными.

Fig. 4. Expression of JNK MAPK, multiplicity of increase in comparison with intact animals.

\section{ЗАКЛЮЧЕНИЕ}

Таким образом, на экспериментальной модели установлены временные сроки и уровень активации JNK МАР-киназных каскадов при асептическом повреждении брюшины. Показано, что при травматическом повреждении брюшины наблюдается активация JNK MAPK каскадов. При этом определено, что для данного процесса характерно двухволновое повышение активности JNK МАРК - на 3-и и 14-е сутки после повреждения брюшины.

Иммуногистохимическое исследование, с учётом использования маркеров, отражающих активность всех трёх JNK-каскадов, не позволило раздельно оценить активность JNK1, 2 и 3 каскада. При применении ПЦР-исследования определено, что в процесс вовлекаются все три каскада, причём на 3-и сутки синхронно активируются все каскады группы JNK (JNK1 повышается в 12,08 раза по сравнению с группой интактных животных, JNK2 - в 8,14 раза, JNK3 - в 10,52 раза). На 14-е сутки наиболее интенсивно повышается активность JNK3 каскада - в 30,8 раза (для JNK1 - в 5,94 раза, JNK2 - в 12,17 раза). Таким образом, получены новые данные о том, что выраженная активация МАРК10 наблюдается не только в головном мозге, сердце и яичках $[7,9]$, но и в серозной оболочке при её повреждении.

Установлена значительная активация исследуемых МАРК каскадов на 14-е сутки после травматического повреждения, что свидетельствует о необходимости длительной профилактики посттравматических изменений, в частности формирования спаечного процесса, в сроки не менее чем 2 недели после травмы.

\section{ЛИТЕРАТУРА REFERENCES}

1. Аюшинова Н.И., Шурыгина И.А., Чепурных Е.Е., Шурыгин М.Г., Григорьев Е.Г. Спаечная болезнь брюшной полости - междисциплинарная проблема // Врач. - 2017. - № 5. - С. 8-10.

Ayushinova NI, Shurygina IA, Chepurnykh EE, Shurygin MG, Grigoriev EG. (2017). Adhesive disease of abdominal cavity - interdisciplinary problem [Spaechnaya bolezn' bryushnoy polosti - mezhdistsiplinarnaya problema]. Vrach, (5), 8-10.

2. Аюшинова Н.И., Шурыгина И.А., Шурыгин М.Г., Лепехова С.А., Балыкина А.В., Малгатаева Е.Р., Попова А.Д., Янкелевич С.А. Экспериментальная модель для разработки способов профилактики спаечного 
процесса в брюшной полости // Сибирский медицинский журнал (Иркутск). - 2012. - Т. 109, № 2. - С. 51-53.

Ayushinova NI, Shurygina IA, Shurygin MG, Lepekhova SA, Balykina AV, Malgatayeva ER, Popova AD, Yankelevich SA. (2012). Experimental model for the development of prevention of adhesions in the abdominal cavity [Eksperimental'naya model' dlya razrabotki sposobov profilaktiki spaechnogo protsessa v bryushnoy polosti]. Sibirskiy meditsinskiy zhurnal (Irkutsk), 109 (2), 51-53.

3. Аюшинова Н.И., Шурыгина И.А., Шурыгин М.Г., Панасюк А.И. Современные подходы к профилактике спаечного процесса в брюшной полости // Сибирский медицинский журнал (Иркутск). - 2011. - Т. 105, № 6. - С. 16-20.

Ayushinova NI, Shurygina IA, Shurygin MG, Panasyuk AI. (2011). Modern approaches to the prevention of intraperitoneal adhesions [Sovremennye podkhody k profilaktike spaechnogo protsessa v bryushnoy polosti]. Sibirskiy meditsinskiy zhurnal (Irkutsk), 105 (6), 16-20.

4. Способ моделирования спаечного процесса в брюшной полости: Патент № 2467401 Рос. Федерация; МПК G09B 23/28 (2006.01) / Аюшинова Н.И., Лепехова С.А., Шурыгина И.А., Рой Т.А., Шурыгин М.Г., Зарицкая Л.В., Гольдберг О.А.; заявитель и патентообладатель Учреждение Российской академии медицинских наук Научный центр реконструктивной и восстановительной хирургии Сибирского отделения РАМН (НЦРВХ СО РАМН). - № 2011131678/14; заявл. 27.07.2011; опубл. 20.11.2012. - Бюл. № 32.

Ayushinova NI, Lepekhova SA, Shurygina IA, Roy TA, Shurygin MG, Zaritskaya LV, Goldberg OA. (2012). Method for modeling the adhesion process in the abdominal cavity: Patent N 2467401 of the Russian Federation [Sposob modelirovaniya spaechnogo protsessa $v$ bryushnoy polosti: Patent № 2467401 Ros. Federatsiya].

5. Шурыгина И.А., Шурыгин М.Г., Зеленин Н.В., Гранина Г.Б. Роль МАР-киназных механизмов в регуляции клеточного роста (обзор литературы) // Сибирский медицинский журнал (Иркутск). - 2009. - Т. 89, № 6. - С. 36-40.

Shurygina IA, Shurygin MG, Zelenin NV, Granina GB. (2009). Role of MAP-kinase mechanisms in the regulation of cell growth [Rol' MAP-kinaznykh mekhanizmov v regulyatsii kletochnogo rosta (obzor literatury)]. Sibirskiy meditsinskiy zhurnal (Irkutsk), 89 (6), 36-40.

6. Bode A., Zigang D. (2007). The functional contrariety of JNK. Mol Carcinogen, 46 (8), 591-598.

7. Barnat M, Enslen H, Propst F, Davis RJ, Soares S, Nothias F. (2010). Distinct roles of c-Jun N-terminal kinase isoforms in neurite initiation and elongation during axonal regeneration. J Neurosci, 30 (23), 7804-7816.

8. Karin M, Gallagher E. (2005) From JNK to pay dirt: jun kinases, their biochemistry, physiology and clinical importance. IUBMB Life, 57 (4-5), 283-295.

9. Mielke K, Herdegen T. (2002). Fatal shift of signal transduction is an integral part of neuronal differentiation: JNKs realize TNFalpha-mediated apoptosis in neuronlike, but not naive, PC12 cells. Mol Cell Neurosci, 20 (2), 211-224.

10. Oltmanns U, Issa R, Sukkar MB, John M, Chung KF. (2003). Role of c-jun N-terminal kinase in the induced release of GM-CSF, RANTES and IL-8 from human airway smooth muscle cells. Br J Pharmacol, 139 (6), 1228-1234.

11. Tian L, Li H, Li Y, Liu K, Sun Y, Cong Z, Luan X, Li Y, Chen J, Wang L, Ren Z, Cong D, Wang H, Pei J. (2018). A combination of chitosan, cellulose, and seaweed polysaccharide inhibits postoperative intra-abdominal adhesion in rats. J Pharmacol Exp Ther, 364 (3), 399-408.

12. Waetzig V, Herdegen T. (2005). Context-specific inhibition of JNKs: overcoming the dilemma of protection and damage. Br J Pharmacol, 26 (9), 455-461.

13. Zhang Y, Li X, Zhang Q, Li J, Ju J, Du N, Liu X, Chen X, Cheng F, Yang L, Xu C, Bilal MU, Wei Y, Lu Y, Yang B. (2014). Berberine hydrochloride prevents postsurgery intestinal adhesion and inflammation in rats.J Pharmacol Exp Ther, 349 (3), 417-426.

\section{Сведения об авторах Information about the authors}

Шурыгина Ирина Александровна - доктор медицинских наук, профессор РАН, заместитель директора по науке, ФГБНУ «Иркутский научный центр хирургии и травматологии» (664003, г. Иркутск, ул. Борцов Революции, 1; тел. (3952) 29-03-69; e-mail: irinashurygina@gmail.com) ๑ http://orcid.org/0000-0003-3980-050X

Shurygina Irina Aleksandrovna - Doctor of Medical Sciences, Professor of RAS, Deputy Director for Science, Irkutsk Scientific Centre of Surgery and Traumatology (664003, Irkutsk, ul. Bortsov Revolyutsii, 1; tel. (3952) 29-03-69; e-mail: irinashurygina@gmail. com) ๑ http://orcid.org/0000-0003-3980-050X

Аюшинова Наталья Ильинична - кандидат медицинских наук, хирург отделения гнойной хирургии № 1, ФГБНУ «Иркутский научный центр хирургии и травматологии» (664049, г. Иркутск, Юбилейный, 100; e-mail: katnatlove@mail.ru) ๑ http://orcid. org/0000-0002-5200-3962

Ayushinova Natalia Ilyinichna - Candidate of Medical Sciences, Surgeon at the Unit of Purulent Surgery N 1, Irkutsk Scientific Centre of Surgery and Traumatology (664049, Irkutsk, Yubileyniy, 100; e-mail: katnatlove@mail.ru) ® http://orcid.org/0000-00025200-3962

Родионова Любовь Викторовна - кандидат биологических наук, заведующая лабораторией клеточной патофизиологии и биохимии, ФГБНУ «Иркутский научный центр хирургии и травматологии» (тел. (3952) 29-03-50; e-mail: greidmacho@yandex. ru) ๑ http://orcid.org/0000-0002-5080-9225

Rodionova Lyubov Viktorovna - Candidate of Biological Sciences, Head of the Laboratory of Cell Pathophysiology and Biochemistry, Irkutsk Scientific Centre of Surgery and Traumatology (tel. (3952) 29-03-50; e-mail: greidmacho@yandex.ru) ® http://orcid. org/0000-0002-5080-9225

Чепурных Елена Евгеньевна - кандидат медицинских наук, учёный секретарь, ФГБНУ «Иркутский научный центр хирургии и травматологии; доцент кафедры госпитальной хирургии, ФГБОУ ВО «Иркутский государственный медицинский университет» Минздрава России (тел. (3952) 29-03-39; e-mail: chepurnikh.ee@yandex.ru) @ http://orcid.org/0000-0002-3197-4276 Chepurnykh Elena Evgenyevna - Candidate of Medical Sciences, Academic Secretary, Irkutsk Scientific Centre of Surgery and Traumatology; Associate Professor at the Department of Advanced Level Surgery, Irkutsk State Medical University (tel. (3952) 2903-39; e-mail: chepurnikh.ee@yandex.ru) @ http://orcid.org/0000-0002-3197-4276

Шурыгин Михаил Геннадьевич - доктор медицинских наук, заведующий научно-лабораторным отделом, ФГБНУ «Иркутский научный центр хирургии и травматологии»; директор по науке и инновационной деятельности, АО «Фармасинтез» (664007, г. Иркутск, ул. Красногвардейская, 3, оф. 3; e-mail: shurygin@rambler.ru) ® http://orcid.org/0000-0001-5921-0318

Shurygin Mikhail Gennadyevich - Doctor of Medical Sciences, Head of the Scientific Laboratory Department, Irkutsk Scientific Centre of Surgery and Traumatology; Director for Science and Innovations, JSC Farmasintez (664007, Irkutsk, ul. Krasnogvardeyskaya, 3, office 3; e-mail: shurygin@rambler.ru) ๑ http://orcid.org/0000-0001-5921-0318 